\title{
MAGNIFICATION THROUGH COMPETITION OF GENETIC DIFFERENCES IN YIELD CAPACITY IN CARP*
}

\author{
ROM MOAV \\ Genetics Department, The Hebrew University, Jerusalem \\ and \\ G. W. WOHLFARTH \\ Fish and Agriculture Research Station, Dor
}

Received 7.xi.73

\begin{abstract}
SUMMARY
Ten experiments were carried out during the period 1961-69. In each experiment a pair of genetically different groups of carp was tested simultaneously for differences in growth rate in mixed ponds as well as in separate ponds. The aim of the experiments was to estimate the genetic correlation of relative growth rate under inter-group competition in mixed ponds and in the absence of intergroup competition in separate ponds. The estimate of the genetic correlation coefficient was found to be 1.0 , and that of the regression coefficient of growth rate in mixed ponds on growth rate in separate ponds was $2 \cdot 0$. The intergroup genetic variance in mixed ponds was four times higher than that of the variance in separate ponds. The higher variance in mixed ponds was partitioned into a component dependent on growth rate in separate ponds and a second independent component. The high genetic correlation means that the dependent component could account for all the amplification of the variance in the mixed ponds and that, apparently, in carp there are no specific genetic factors affecting growth rate under competition. The practical implications of this result for carp breeding is that selection for the improvement of yield capacity can be performed more effectively in mixed ponds than in separate ponds. A theoretical model for analysis of competition is presented and discussed.
\end{abstract}

\section{INTRODUGTION}

IN selection programmes of fish aimed at improving yield capacity the units under selection (individuals or groups of fish) may be grown in separate ponds (or other containers), i.e. in the absence of competition between the units of selection. The major advantage of this method is that yield capacity is measured directly. Its disadvantages are the need for a large number of ponds (containers) to overcome the confounding of genetic variation with environmental differences between containers. Because of these drawbacks, selection is usually performed on individuals or groups grown within the same pond (mixed ponds). Here the fish are subjected to mutual competitive interactions, therefore yield capacity cannot be measured directly and the measured and selected character is relative growth rate in mixed stocking. Since the breeders' interest is in yield capacity, evaluation of results obtained from mixed ponds requires an estimate of the genetic correlation of growth rate in the presence and absence of competition. The critical importance of this association has been pointed out (Schaeperclaus, 1958; Kirpichnikov, 1966), but no attempt has been made to estimate it in the past.

If competitive ability is unrelated or negatively correlated with yield capacity, growth rate under competition may be a poor measure of yield capacity. But if competitive ability is positively correlated with yield

* This paper is part based on the Ph.D. thesis of S. W. Wohlforth submitted to the Hebrew University, Jerusalem. 
capacity, genetic differences in yield capacity will be magnified in mixed stocking. In the latter case relative growth rate in mixed stocking may be a better measure of yield capacity than growth rate in separate ponds.

The relationship of competitive ability to selection for higher yields in cultivated plants, particularly cereals, has been a subject of numerous investigations (Sakai, 1955; Donald, 1963; McGilchrist and Trenbath, 1971; Norrington-Davies, 1972; and others). Sammeta and Levins (1970) reviewed an extensive list of reports on competition in plants and animals and concluded: ". . . The relation between competitive ability and other fitness components may be different in different organisms and competitive situations. So it is important not to assume a priori that productivity and competitive ability are positively correlated."

In order to estimate the correlation between growth rate in separate and in mixed ponds in carp a series of 10 experiments was carried out during the period 1961-69. In each experiment two genetically different groups of carp were tested simultaneously in mixed and separate ponds. A high genetic correlation and a strong magnification of inter-group differences in mixed ponds were found. These experiments, their analysis and interpretation are described in the present paper.

\section{The Genetic STOGKS}

The common carp (Cyprinus carpio L.) has been cultivated in ponds in China since at least the fifth century B.a. In the Middle Ages it was introduced to Europe for use as a cultivated fish (Hickling, 1968). Carp cultivation in ponds in Israel was initiated in 1939 through a number of introductions, mainly from Europe (Tal and Shelubsky, 1952; Yashouv, 1955;

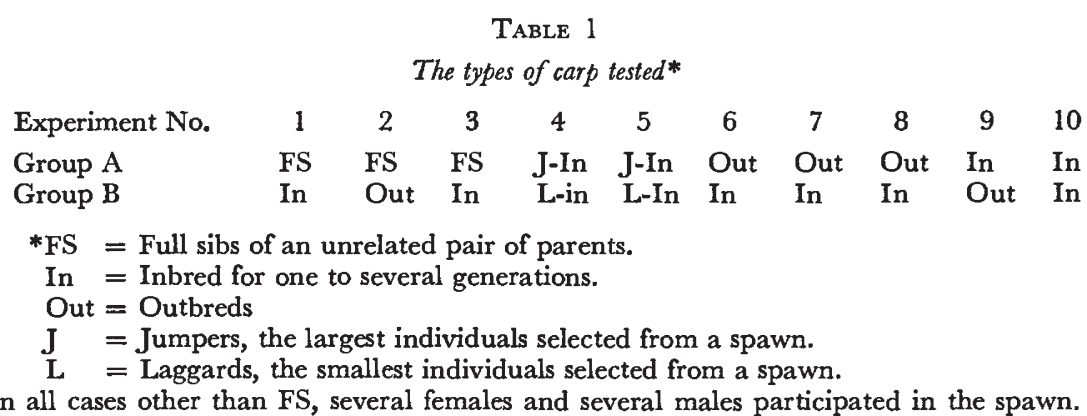

Moav et al., 1964). The carp population of Israel, including all the groups tested in this series of experiments, is thus mostly of European descent.

The intra-group relations of the tested groups, i.e. full-sibs, inbreds and outbreds, are listed in table 1 . The two groups of carp tested in eight of the ten experiments were chosen from the 15 to 25 groups of carp tested annually in our research programme (Wohlfarth et al., 1965; Moav and Wohlfarth, 1966). A deliberate non-random choice of dissimilar groups ensured the presence of genetic differences between the two groups tested in each experiment. Experiments 4 and 5 differed from the other eight experiments since here the two tested groups consisted of the largest and smallest individuals selected from the same spawn. Thus, in these two experiments, the 
expected difference between the two groups was not only of genetic origin but also of environmental origin of the so-called developmental type.

\section{Experimental methods}

All the tests were carried out in earthen ponds. In experiments 1 to 5, both separate and mixed ponds were small experimental ponds of 400 or $1000 \mathrm{~m}^{2}$ at the Fish Aquaculture Research Station, Dor. The same ponds also served as the separate ponds in experiments $6-10$, but the mixed ponds in these experiments were much larger $\left(5000\right.$ to $\left.30,000 \mathrm{~m}^{2}\right)$ and were located at the fish farms of the Carp Breeders Union (Wohlfarth et al., 1965). Since in mixed ponds there is no confounding of pond differences with genetic differences between the groups, each mixed pond could be located at a different farm. The use of larger ponds enabled larger samples of fish to be tested. In addition to the pairs of groups relevant to the present study, the large mixed ponds in experiments 6 to 10 were stocked with other groups of fish. These are considered in the context of the present study as a part of the external environment. Details of the mixed ponds of the experiment carried out in 1964 are given by Wohlfarth et al. (1965).

Spawning was carried out in late April, each group in a different pond. As a rule, the fish spawned within 12 hours of being introduced into the spawning pond, and the eggs hatched within three to four days. A few weeks after spawning, fry were transferred from the spawning ponds to the nursery ponds, where they grew to a mean weight of 20 to $50 \mathrm{~g}$. The nursed fingerlings were marked by branding (Moav et al., 1960) and stocked into the experimental ponds in June to August. Experiments 1 and 2 differed from the remaining experiments in that they were initiated in February and March, respectively, and were stocked with fish spawned during the previous year. These fish differed from those of other experiments in their age, sexual maturity and higher initial weights. The tests lasted from 70 to 140 days. At the termination of each test, the ponds were drained and all the fish removed, sorted, counted and weighed.

\section{Corrections for absolute meAn Weights, initial Weights AND FINAL POND DENSITY}

\section{(i) Absolute mean weight}

The final mean weights of the tested groups varied considerably between experiments and even between different mixed ponds of the same experiment. This variation was largely due to environmental factors such as number of fish per unit area, pond fertility, management, etc. Since the standarddeviation of weight in carp is approximately proportional to the mean weight, an adjustment to a computed mean weight of $500 \mathrm{~g}$ served to reduce the variation between standard-deviations of the different experiments. The factor $500 \mathrm{~g}$ was chosen for the correction because it is a round number close to the mean of all the ten experiments and to the mean of the market weight of carp in Israel. The correction was made by multiplying the difference in weight gains between the two tested groups, $(d)$, by the factor $(500 / W$. ). In separate ponds $W$. was the mean weight of the two tested groups over all the separate ponds of a given experiment. The large weight differences between different mixed ponds even of the same experiment (especially in experiments 
6-10) required an individual adjustment for each mixed pond. Thus for a given mixed pond, $W$. was the mean weight of the two tested progenies in that pond.

\section{(ii) Initial weight}

Considerable variation in mean initial weight occurred between the two groups tested in each experiment. This was a result of lack of complete control over environmental conditions in the nursery ponds. Since weight gain in fish is positively correlated with initial weight, groups stocked at higher initial weights (due to chance favourable conditions in nursery ponds) tend to grow faster than those stocked at lower initial weights. In order to remove this bias the observed weight gains were corrected as follows (Wohlfarth and Moav, 1972): $\mathrm{Y}=\mathrm{Y}^{\prime}-b(X-X$.), where

$$
\begin{aligned}
\mathrm{Y}= & \text { corrected weight gain (it is uncorrelated with initial weight and taken } \\
& \text { as a measure of growth capacity), } \\
\mathrm{Y}^{\prime}= & \text { observed weight gain, } \\
X= & \text { initial weight, } \\
X .= & \text { mean initial weight of the two tested groups, and } \\
b= & \text { coefficient of linear regression of weight gain on initial weight. }
\end{aligned}
$$

$b$ is a decreasing function of initial weight and an increasing function of weight gain. Therefore it requires empirical estimation for different experiments (Wohlfarth, 1971; Wohlfarth and Moav, 1971). In the mixed ponds of the present experiments $b$ varied between 2 to 5 . In separate ponds the value of $b$ is considerably lower than in mixed ponds, and therefore no correction was applied. The higher value of $b$ in mixed ponds is due to competitive interactions between the mixed groups which magnify differences, resulting from variation in initial weights (Wohlfarth, 1971).

\section{(iii) Final fish density}

The separate ponds within each experiment were of equal size, stocked with equal number of fish and treated similarly. Nevertheless, during the test period unequal mortality created some differences in fish number. Since weight gain is a decreasing function of density (number of fish per unit area) (Hepher, 1967), the average weight gain per fish tended to be higher in ponds with higher mortality. This distortion was corrected by multiplying the average weight gain of each pond by the factor $(n / n$.), when $n$ is the final number of fish in a given pond and $n$. is the average of all the ponds of a given experiment. This adjustment makes the assumption that yield is independent of fish density, i.e. a complete compensation of mean growth per fish for differences in density. This seems a reasonable assumption when relative mortality is low and varies little between ponds.

\section{MODELS}

We shall treat the tested groups of fish as a sample drawn from a population of average genotypes grown under two sets of environmental circumstances, separate ponds and mixed ponds, defined respectively Environment one $\left(\mathbf{E}_{1}\right)$ and Environment two $\left(\mathbf{E}_{2}\right)$. The genetic value of growth rate in $\mathbf{E}_{\mathbf{1}}$ is designated $g_{1}$ (measured as a deviation from the population mean), and its variance $\begin{gathered}\sigma_{2}^{g_{1}} \\ \boldsymbol{g}_{1}\end{gathered}$ The variable $g_{1}$ may be considered as a measure of the relative efficiency of 
exploiting external resources in the absence of competition with other groups of carp and is referred to as yield capacity. The genetic value of growth rate in $\mathbf{E}_{2}$ designated $\left(g_{2}\right)$, and again measured as a deviation from the population mean in $\mathbf{E}_{2}$, may be presented as a linear function of three components: $g_{1}$, competitive ability which is dependent on $g_{1}\left(\alpha g_{1}\right)$, and competitive ability which is independent of $g_{1}(I)$,

$$
g_{2}=g_{1}+\alpha g_{1}+I=(1+\alpha) g_{1}+I \text {. }
$$

$\alpha$ is the amplification factor measuring the average proportion of genetic changes in $\mathbf{E}_{2}$ due to competition which is fully predictable by growth capacity in $\mathbf{E}_{1}$. On the other hand, $I$ is unrelated to efficiency of exploiting external resources. For distinction between the two genetic components of competition $\alpha g_{1}$ and $I$, the latter will be referred to as the genetic component of independent aggressiveness.

The genetic parameters of interest, derived from the model defined by equation 1, may now be presented.

The genetic variance in Environment 2,

$$
\sigma_{g_{2}}^{2}=(1+\alpha)^{2} \sigma_{g_{1}}^{2}+\sigma_{I}^{2}
$$

The difference in genetic variances of $\mathrm{E}_{1}$ and $\mathrm{E}_{2}$

$$
\left(\sigma_{g_{2}}^{2}-\sigma_{g_{1}}^{2}\right)=\alpha(2+\alpha) \sigma_{g_{1}}^{2}+\sigma_{I}^{2} .
$$

The covariance of $g_{1}$ and $g_{2}$,

$$
\sigma_{12}=(1+\alpha) \sigma_{g_{1}}^{2}
$$

The coefficient of genetic regression of $g_{2}$ on $g_{1}$,

$$
\beta_{g}=\frac{\sigma_{12}}{\sigma_{g_{1}}^{2}}=(1+\alpha)
$$

The coefficient of genetic correlation of $g_{2}$ and $g_{1}$,

$$
\rho_{g}=\frac{(1+\alpha) \sigma_{g_{1}}^{2}}{\sigma_{g_{1}}\left((1+\alpha)^{2} \sigma_{g_{1}}^{2}+\sigma_{I}^{2}\right)^{\frac{1}{2}}}=\left(\frac{(1+\alpha)^{2} \sigma_{g_{1}}^{2}}{(1+\alpha)^{2} \sigma_{g_{1}}^{2}+\sigma_{I}^{2}}\right)^{\frac{1}{2}}
$$

Note than when $\sigma_{I}^{2}=0$ then $\beta_{g}=1$.

The fundamental biological difference between the two genetic parameters $I$ and $\alpha$ (or $\alpha g_{1}$ ) is shown by their different contributions to the above regression and correlation coefficients. Both $\alpha$ and $I$ increase the genetic variability in $E_{2}$ over that in $E_{1}$, and both result from inter-genotype competition. However, $\alpha$ does not change the rankings of the different genotypes (groups) while $I$, which may be controlled by a different set of genes than $g_{1}$, reduces the correlation between growth rates of the two environments.

Conventionally the present problem is handled by a different model than that defined in equation 1 . The conventional linear model partitions the $j$ th genotype of the $i$ th environment into the following three components: the environmental effect $\left(a_{i}\right)$, the average genetic effect $\left(g_{i}\right)$ and the genotypeenvironment interactions $\left(g a_{i j}\right)$,

$$
g_{i j}=a_{i}+g_{j}+g a_{i j}
$$

(note that $a_{i}$ is absent from equation 2 because $g_{2}$ was defined as a deviation from the mean of environment 2 rather than from the general mean). 
$i=1$ and $i=2$ represent, respectively, separate and mixed stockings and $j=1,2, \ldots, f$ the tested groups (genotypes). The interaction $g a_{i j}$ can be divided into two components, one a linear function of the average genotype $\left(\gamma g_{j}\right)$ and the second independent of $g_{j},\left(I^{\prime}\right)$. That is:

$$
g a_{i j}=\gamma_{i} g_{j}+I_{i j}^{\prime}
$$

and by substitution into equation 7 ,

$$
g_{i j}=a_{i}+g_{j}+\left(\gamma_{i} g_{j}+I_{i j}^{\prime}\right)=a_{i}+\left(1+\gamma_{i}\right) g_{j}+I_{i j}^{\prime} \text {. }
$$

This equation has the advantage that it can be applied to more than two stocking conditions (environments), and when only two stocking conditions are involved, as in the present case, it can be simplified as follows:

so that

$$
\gamma=\gamma_{2}=-\gamma_{1} \text { and } I^{\prime}=I_{2}^{\prime}=-I_{1}^{\prime}
$$

while

$$
g_{1 j}=a_{1}+g_{j}-\gamma g_{j}-I_{j}^{\prime}=a_{1}+(1-\gamma) g_{j}-I_{j}^{\prime}
$$

or, generally,

$$
g_{2 j}=a_{2}+g_{j}+\gamma g_{j}+I_{j}^{\prime}=a_{2}+(1+\gamma) g_{j}+I_{j}^{\prime}
$$

$$
g_{i j}=a_{i}+\left[1+(-1)^{i} \gamma\right] g_{j}+(-1)^{i} I_{j}^{\prime} \text {. }
$$

When $i=2$ the coefficient in front of $g_{j}$ is $(1+\gamma)$ and it equals the regression coefficient of mixed stocking $(i=2)$ on the average genotype (over mixed and separate stocking). Similarly, $(1-\gamma)$ is the regression coefficient of separate stocking on the average genotype. The coefficient $(-1)^{i}$ obviates the need of an absolute value which was used in similar circumstances (e.g. Bucio Alanis, 1966).

$\gamma$ and $I^{\prime}$ of equations 9 and 10 are equivalent, respectively, to $\alpha$ and $I$ of equation 2, and their functional relationships are given by the following two equations,

$$
\gamma=\frac{\alpha}{2+\alpha} \text { and } I^{\prime}=\frac{I}{2+\alpha} .
$$

Bucio Alanis (1966) partitioned the genotype-environment interaction term into a linear function of the environmental deviation $\left(\beta_{j} a_{i}\right)$ and a residual independent component $\left(\delta_{i j}\right)$. This concept was further elaborated in a series of reports (e.g. Perkins and Jinks, 1968; Freeman and Perkins, 1971). Their model, corresponding to equation 9, can be presented (in the present notations) as

$$
g_{i j}=\left(1+\beta_{j}\right) a_{i}+g_{j}+\delta_{i j}
$$

In all these reports the writers were primarily interested in expressing genotype-environment interactions as functions of the environment $\left(a_{i}\right)$. This, in contrast with the present study where the interaction is expressed as a function of the genotype $\left(g_{j}\right)$. The difference is due to the fact that here interest is centred exclusively on the correlation of performance in the absence and the presence of inter-genotype competition. The environmental deviation $a_{i}$ represents different states of intra-specific competition rather than variation in physical attributes. Furthermore, for the present problem there is no need to estimate $a_{i}$, and it even may be assumed to be zero (for this reason it has been omitted from equation 1 ). The interaction term 
measures the specific effects of competition on the individual genotype and therefore it is best presented as a function of the genotype $\left(g_{j}\right)$ rather than the environment $\left(a_{i}\right)$.

The regression coefficient $\beta_{j}$ of equation 12 may be due to two causes, differing widely in their biological significance. The first cause is a scale effect produced by the well-known phenomenon of positive correlation between the intra-environment variation and the environment's mean. This factor cannot be considered a true genetic interaction in the sense of specific

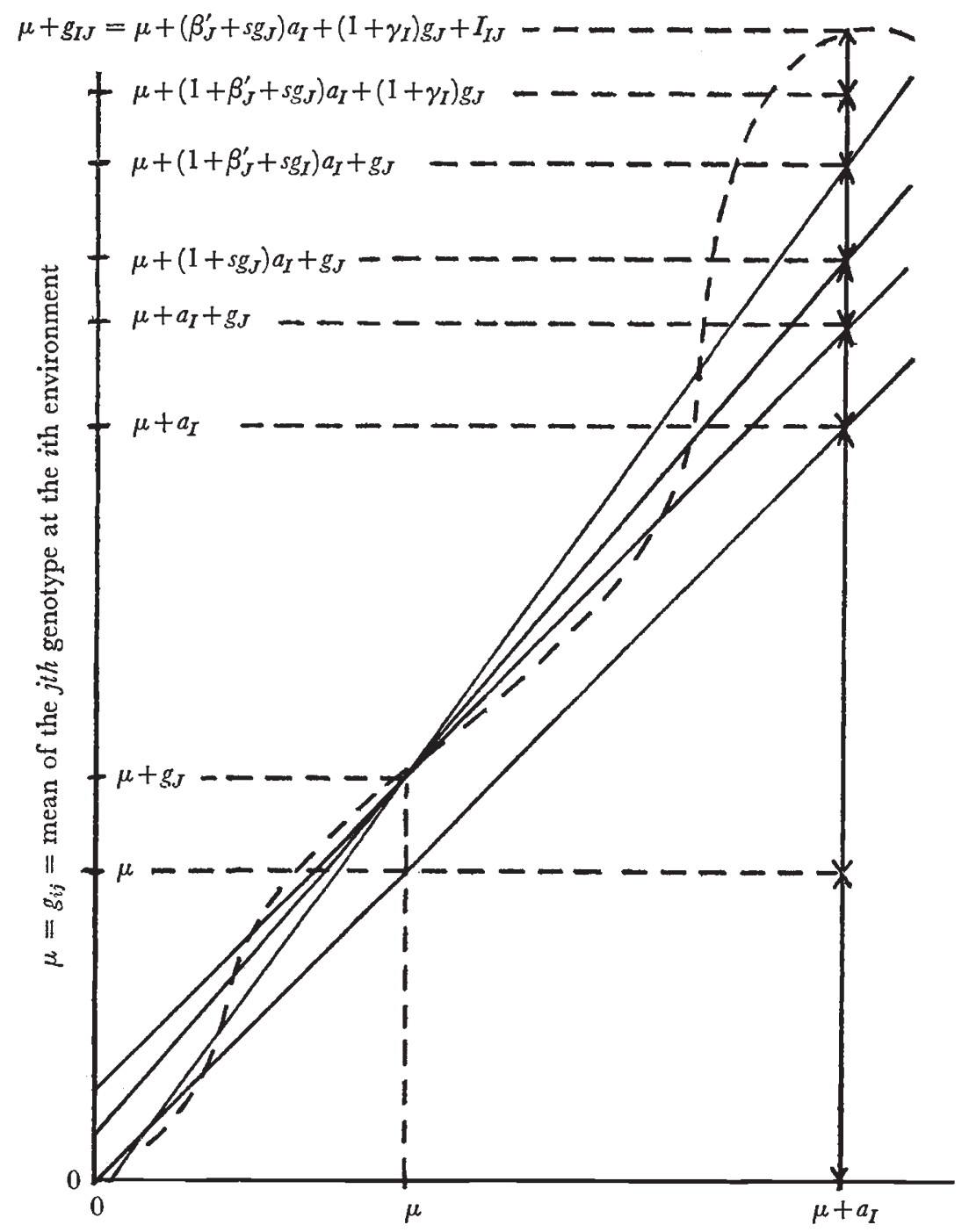

$\mu_{i}=\mu+a_{i}=$ average quality of the $i$ th environment

Fig. 1.-Graphic presentation of a genotype as a function of the environment. (Linear components are those of equation 14. An arbitrary genotype $\mathcal{f}$ was partitioned at an arbitrary environment $I$. Wavy curve corresponds to the " true" functional relationship of the genotype $\mathcal{F}$ to the environment). 
adaptation (sensitivity) to varying environments. The second cause is sensitivity or responsiveness to an underlaying environmental variable which cannot be expressed as a scale function. The distinction between these two causes was described by Robertson (1959) and further elaborated with examples and implications to animal breeding by Dickerson (1962). In order to separate the effects of the above two causes the regression term $\beta_{j} a_{i}$ of equation 12 may be broken as follows:

$$
\beta_{j} a_{i}=s g_{j} a_{i}+\beta_{j}^{\prime} a_{i}
$$

When $s$ is a scale coefficient and $\beta_{j}^{\prime}=\left(\beta_{j}-s g_{j}\right)$ is a function of the environment after elimination of the scale effects. Substitution into equation 12 yields

$$
g_{i j}=\left(1+\beta_{j}^{\prime}\right) a_{i}+g_{j}+s g_{j} a_{i}+\delta_{i j}
$$

Now the Bucio Alanis' expression of the interaction as a function of the environment (equation 12 and 13) and the present expression of the interaction as a function of the genotype $\left(g_{j}\right)$ may be combined by partitioning the residual interaction term $\delta_{i j}$ into a function of the genotype plus an independent residual term $\left(\delta_{i j}=\alpha_{i} g_{j}+I_{i j}^{\prime}\right)$ and substituting into equation 13:

$$
g_{i j}=\left(1+\beta_{j}^{\prime}\right) a_{i}+\left(1+\gamma_{i}\right) g_{j}+s g_{j} a_{i}+I_{i j}^{\prime}
$$

The last equation represents a complete partitioning of the genotypeenvironment interaction where each one of the four components $\left(\gamma_{i} g_{j}, \beta_{j}^{\prime} a_{i}\right.$, $s g_{i} a_{i}$ and $I_{i j}^{\prime}$ ) has a distinct biological significance, each may be (at least partially) under different genetic control, and each has different implications to selection and breeding.

Freeman and Perkins (1971) showed that when the environment is measured independently of the data used for estimating the regression coefficient $\beta_{j}$ (of equation 12 or $\beta_{j}$ plus $s g_{j}$ of equation 14) then $\bar{\beta}_{j}$ the mean of all the $\beta_{j}$ 's, is not necessarily equal to one. Consequently, equation 14 may assume an even more generalised form by substituting $\left(\bar{\beta}+\beta_{j}^{\prime}\right) a_{i}$ for $\left(1+\beta_{j}^{\prime}\right) a_{i}$. A graphical illustration of equation 14 is presented in fig. 1 when $g_{i j}$ and its components were expressed as functions of the environment $\left(\mu+a_{i}\right.$, when $\mu$ is the general mean). For the illustration a hypothetical specific genotype $g_{J}$ was broken down at the arbitrarily chosen environment $a_{I}$. The various hypothetical regression lines were drawn and the accumulation of the components from $\mu$ to the full $g_{i j}+\mu$ are shown along the vertical axis. The wavy curve presents the actual ("true ") functional relationship of the specific genotype $g_{j}$ to $\left(\mu+a_{i}\right)$.

The independent measure of the environment $(z)$ suggested by Freeman and Perkins (1971) could probably be applied to studies of competition if $z$ is defined as a degree of crowding, proportion of other genotypes in a mixture, etc.

\section{EXPERimental RESUlts}

Relevant details of the ten experiments are given in table 2, while the results of separate ponds and mixed ponds are summarised, respectively, in tables 3 and 4. Full details of experiments 1 to 9 were given by Wohlfarth 
TABLE 2

Details of the ten experiments

\begin{tabular}{|c|c|c|c|c|c|c|}
\hline $\begin{array}{l}\text { Experiment } \\
\text { No. }\end{array}$ & $\begin{array}{l}\text { Method of } \\
\text { stocking } \\
\text { the ponds }\end{array}$ & $\begin{array}{c}\text { Number } \\
\text { of } \\
\text { ponds* }\end{array}$ & $\begin{array}{l}\text { Pond's } \\
\text { area in } \\
1000 \mathrm{~m}^{2}\end{array}$ & $\begin{array}{l}\text { Number } \\
\text { of fish } \\
\text { per pond }\end{array}$ & $\begin{array}{l}\text { Date of } \\
\text { initiation } \\
\text { of the test }\end{array}$ & $\begin{array}{l}\text { Duration of } \\
\text { the test } \\
\text { (days) }\end{array}$ \\
\hline 1 & $\begin{array}{l}\text { Separate }\left(E_{1}\right) \\
\text { Mixed }\left(E_{2}\right)\end{array}$ & $\left.\begin{array}{r}10 \\
5\end{array}\right\}$ & 1 & 175 or 250 & 2.ii.61 & 77 \\
\hline 2 & $\begin{array}{l}E_{1} \\
E_{2}\end{array}$ & $\left.\begin{array}{r}12 \\
6\end{array}\right\}$ & 1 & 200 & 7.iii.61 & 76 \\
\hline 3 & $\begin{array}{l}E_{1} \\
E_{2}\end{array}$ & $\left.\begin{array}{r}12 \\
4\end{array}\right\}$ & 1 & 252 & 6.vi.61 & 89 \\
\hline 4 & $\begin{array}{l}E_{1} \\
E_{2}\end{array}$ & $\left.\begin{array}{r}10 \\
5\end{array}\right\}$ & $0 \cdot 4$ & 80 & 7.viii.61 & 97 \\
\hline 5 & $\begin{array}{l}E_{1} \\
E_{2}\end{array}$ & $\left.\begin{array}{r}20 \\
5\end{array}\right\}$ & $0 \cdot 4$ & 90 & 5.viii.62 & 92 \\
\hline $6 \dagger$ & $\begin{array}{l}E_{1} \\
E_{2}\end{array}$ & $\begin{array}{r}20 \\
6\end{array}$ & $\begin{array}{c}1 \\
5 \text { to } 30\end{array}$ & $\begin{array}{l}250 \\
100\end{array}$ & $\begin{array}{c}\text { 9.ix.62 } \\
\text { 12.vii.62 }\end{array}$ & $\begin{array}{c}70 \\
101-140\end{array}$ \\
\hline $7 \ddagger$ & $\begin{array}{l}E_{1} \\
E_{2}\end{array}$ & $\begin{array}{l}8 \\
4\end{array}$ & $\begin{array}{c}0.2 \\
15 \text { to } 25\end{array}$ & $\begin{array}{c}37 \\
30 \text { to } 120\end{array}$ & $\begin{array}{r}\text { 18.vii.63 } \\
\text { 8.vii.63 }\end{array}$ & $\begin{array}{c}86 \\
98-139\end{array}$ \\
\hline 8 & $\begin{array}{l}E_{1} \\
E_{2}\end{array}$ & $\begin{array}{r}10 \\
4\end{array}$ & $\begin{array}{c}0.4 \\
15 \text { to } 25\end{array}$ & $\begin{array}{c}100 \\
55 \text { to } 120\end{array}$ & $\begin{array}{l}\text { 9.vii.64 } \\
\text { 3.vii.64 }\end{array}$ & $\begin{array}{c}76 \\
90-141\end{array}$ \\
\hline $9 \ddagger$ & $\begin{array}{l}E_{1} \\
E_{2}\end{array}$ & $\begin{array}{r}18 \\
5\end{array}$ & $\begin{array}{c}0.2 \\
15 \text { to } 25\end{array}$ & $\begin{array}{r}40 \\
175\end{array}$ & $\begin{array}{l}\text { 28.vii. } 66 \\
\text { 13.vii.66 }\end{array}$ & $\begin{array}{c}110 \\
109-135\end{array}$ \\
\hline 10 & $\begin{array}{l}E_{1} \\
E_{2}\end{array}$ & $\begin{array}{r}17 \\
4\end{array}$ & $\begin{array}{c}0.4 \\
20 \text { to } 30\end{array}$ & $\begin{array}{c}85 \\
50 \text { to } 200\end{array}$ & $\begin{array}{l}\text { 28.vii.69 } \\
\text { 10.vii.69 }\end{array}$ & $\begin{array}{c}119 \\
115-144\end{array}$ \\
\hline
\end{tabular}

* The number of separate ponds $\left(E_{1}\right)$ stocked by each one of the two tested groups of each experiment was half the value recorded in this column. In experiment 10 , one group was stocked into nine ponds and the second into eight ponds.

† In experiments 6 to 10 large ponds were used for the mixed stocking. These ponds were stocked with several groups of carp in addition to the pair dealt with here. The " number of fish" recorded in the table is an average per group of the two pertinent groups. When large variation existed, two values were recorded to cover the whole range of variation. The mixed ponds in these experiments were each stocked on the same day but emptied on different days. The two values for " duration of the tests" cover the whole range.

$\ddagger$ In experiments 7 and 9 , the unit of the "separate stocking " $\left(E_{1}\right)$ was half a pond of $400 \mathrm{~m}^{2}$ divided by wire netting.

TABLE 3

Summary of the results of separate ponds

Experiment

No.

1

2

3

4

5

6

7

8

9

10

$\begin{array}{rr}\text { Group A } & \text { Group B } \\ 88 & 99 \\ 206 & 259 \\ 25 & 34 \\ 13 & 13 \\ 43 & 42 \\ 73 & 74 \\ 45 & 37 \\ 15 & 12 \\ 47 & 48 \\ 33 & 30\end{array}$

$\begin{array}{ccc}\text { Group A } & \text { Group B } & \text { Mean } \\ 406 & 374 & 390 \\ 292 & 242 & 267 \\ 464 & 413 & 439 \\ 450 & 419 & 435 \\ 482 & 451 & 467 \\ 248 & 241 & 245 \\ 766 & 709 & 738 \\ 576 & 548 & 564 \\ 560 & 556 & 558 \\ 753 & 700 & 728\end{array}$

Weight gains $(\mathrm{g})^{*}$

* $d_{1}^{\prime}=$ difference in weight gain adjusted to an absolute weight of $500 \mathrm{~g}$.

$T_{1}=(500 / W$. $)$ when $W .=$ average absolute weight of all the separate ponds of a given experiment.

Note that the results of separate ponds were not corrected for differences in initial weights (see text), hence the difference between this table and table 4. 
(1971). The difference in separate ponds between the two tested groups of each experiment was designated $d_{1}$, and their difference in mixed ponds $d_{2}$. Thus,

$$
d_{1}=\left(A_{1}-B_{1}\right) \text { and } d_{2}=\left(A_{2}-B_{2}\right) .
$$

Table 5, $\mathbf{A}$ and $\mathbf{B}$, show the differences in relative growth rate between the pairs of genetic groups in separate and mixed ponds for the ten experiments. The tables also provide estimates for the "error" variances due to

TABLe 5

Differences in weight gains in separate and mixed ponds, Standard Errors (SE) of these differences and the environmental (error) variances $\left(\mathrm{s}_{\mathrm{E}}^{2}\right)$ of the ten experiments

(The indices 1 and 2 refer, respectively, to separate and mixed ponds. $K=$ number of ponds. Values of $d_{1}, d_{2}, d_{1}^{\prime}$ and $d_{2}^{\prime}$ taken from tables 3 and 4. .)

A. RESUlts NOT CORREGTED FOR ABSOLUTE WEiGHTS

\begin{tabular}{|c|c|c|c|c|c|c|c|c|}
\hline $\begin{array}{c}\text { Experiment } \\
\text { No. }\end{array}$ & $\begin{array}{c}\text { Difference } \\
\text { in separate } \\
\text { ponds }(\mathrm{g}) \\
d_{1}\end{array}$ & $\mathrm{SE}_{1}^{*}$ & $\begin{array}{c}\text { Difference } \\
\text { in mixed } \\
\text { ponds }(\mathrm{g}) \\
d_{2}\end{array}$ & $\mathrm{SE}_{2}^{*}$ & $\kappa_{1}$ & $s_{E_{1}}^{2}$ & $\kappa_{2}$ & $s_{E_{2}}^{2}$ \\
\hline 1 & 32 & 11.9 & 34 & $7 \cdot 4$ & 5 & 714 & 5 & 277 \\
\hline 2 & 50 & $7 \cdot 7$ & 65 & $9 \cdot 0$ & 6 & 353 & 6 & 487 \\
\hline 3 & 51 & $9 \cdot 2$ & 58 & 9.9 & 6 & 507 & 4 & 396 \\
\hline 4 & 31 & $16 \cdot 6$ & 81 & $9 \cdot 2$ & 5 & 1372 & 5 & 421 \\
\hline 5 & 31 & 17.4 & 36 & $5 \cdot 6$ & 10 & 3032 & 5 & 154 \\
\hline 6 & 7 & $5 \cdot 0$ & 57 & $15 \cdot 3$ & 10 & 252 & 6 & 1411 \\
\hline 7 & 57 & $19 \cdot 0$ & 131 & 14.0 & 4 & 1437 & 4 & 788 \\
\hline 8 & 28 & $14 \cdot 0$ & 58 & $7 \cdot 2$ & 5 & 982 & 4 & 210 \\
\hline 9 & 4 & 8.8 & 9 & $8 \cdot 3$ & 9 & 704 & 5 & 345 \\
\hline 10 & 53 & 19.3 & 51 & 3.8 & 8 & 2989 & 4 & 57 \\
\hline Mean & $34 \cdot 4$ & 4.4 & 57.9 & $3 \cdot 1$ & - & 1234 & - & 455 \\
\hline
\end{tabular}

B. RESULTS CORRECTED FOR ABSOLUTE WEIGHTS

\section{Experiment}

$\begin{array}{ccrc}\text { No. } & d_{1}^{\prime} & \mathrm{SE}_{1}^{\prime *} & d_{2}^{\prime} \\ 1 & 33 & 12 \cdot 3 & 33 \\ 2 & 49 & 7 \cdot 4 & 64 \\ 3 & 55 & 9 \cdot 9 & 60 \\ 4 & 33 & 17 \cdot 7 & 88 \\ 5 & 32 & 17 \cdot 1 & 35 \\ 6 & 11 & 7 \cdot 9 & 45 \\ 7 & 37 & 12 \cdot 2 & 95 \\ 8 & 24 & 12 \cdot 2 & 41 \\ 9 & 3 & 7 \cdot 3 & 6 \\ 10 & 35 & 17 \cdot 7 & 45 \\ \text { Mean } & 31 \cdot 2 & 3 \cdot 9 & 51 \cdot 2\end{array}$

$\begin{array}{rrrrr}\mathrm{SE}_{2}^{\prime *} & \kappa_{1} & s_{E_{1}}^{\prime 2} & \kappa_{\mathrm{a}} & s_{E_{\mathrm{q}}}^{\prime 2} \\ 6 \cdot 6 & 5 & 762 & 5 & 215 \\ 9 \cdot 5 & 6 & 339 & 6 & 543 \\ 9 \cdot 6 & 6 & 586 & 4 & 370 \\ 8 \cdot 4 & 5 & 1566 & 5 & 358 \\ 5 \cdot 6 & 10 & 2926 & 5 & 154 \\ 9 \cdot 8 & 10 & 627 & 6 & 583 \\ 7 \cdot 1 & 4 & 592 & 4 & 205 \\ 3 \cdot 6 & 5 & 740 & 4 & 49 \\ 8 \cdot 8 & 9 & 487 & 5 & 395 \\ 5 \cdot 1 & 8 & 1296 & 4 & 104 \\ 2 \cdot 5 & - & 992 & - & 297 \cdot 6\end{array}$

* $\mathrm{SE}=\mathrm{Standard}$ error of the mean $=\left(s_{E}^{2} / K\right)^{ \pm}$. SE of the means of all the ten experiments $=$ average $\left.\left(s_{E}^{2} / K\right) / 10\right)^{\frac{1}{2}}$.

environmental variation associated with the estimates of the genetic parameters. $s_{E_{1}}^{2}$ is the variance between the means of separate ponds stocked with the same genetic group, and $s_{E_{2}}^{2}$ is the variance between the deviations of the same group around the means of the mixed ponds. The group with the higher weight gain in separate ponds was designated A while the group with the lower weight gain was designated B. Thus, by definition, all the $d_{1}$ values 
(tables 3 and 5) were positive. All ten $d_{2}$ values were also found to be positive (tables 4 and 5) showing that the rankings of the $A$ and $B$ groups were identical in the separate and mixed ponds of all the ten experiments.

It can be shown that the phenotypic correlation between weight gain in separate and mixed ponds is equal to the coefficient of correlation of $d_{1}$ and $d_{2}\left(r_{d_{1} d_{2}}\right)$,

$$
\hat{r}_{d_{1} d_{2}}=\frac{\Sigma d_{1} d_{2}}{\sqrt{\left(\Sigma d_{1}^{2}\right)\left(\Sigma d_{2}^{2}\right)}}
$$

(see equations 13A, 14A and 15A in the appendix).

The estimates of this parameter obtained from the observed results and results corrected for absolute weights were very high, 0.92 and 0.91 respectively $\left(r_{d_{1} d_{2}}\right.$, table 6$)$. This means that over 80 per cent $\left(r^{2}=\right.$ the coefficient of determination) of the between-group variations in mixed ponds can be

\section{TABLE 6}

Estimates of genetic and phenotypic parameters of weight gain in mixed and separate ponds

\begin{tabular}{|c|c|c|c|c|}
\hline & & & Estin & tes* \\
\hline & Estimated parameter & Equations & 1 & 2 \\
\hline$\sigma_{d_{1}}^{2}$ & Variance between groups in separate ponds & $13 \mathrm{~A}$ & 1495 & 1193 \\
\hline$\sigma_{d_{2}}^{2}$ & Variance between groups in mixed ponds & $14 \mathrm{~A}$ & 4299 & 3255 \\
\hline$\sigma_{d_{1} d_{2}}$ & $\begin{array}{l}\text { Covariance of inter-group differences in mixed } \\
\text { and separate ponds }\end{array}$ & $15 \mathrm{~A}$ and $20 \mathrm{~A}$ & 2312 & 1813 \\
\hline$r_{d_{1} d_{2}}$ & $\begin{array}{l}\text { Correlation of group means in mixed and } \\
\text { separate ponds }\end{array}$ & 15 & 0.91 & 0.92 \\
\hline$\sigma_{g_{1}}^{2}$ & $\begin{array}{l}\text { Genetic variance between groups in separate } \\
\text { ponds }\end{array}$ & $18 \mathrm{~A}$ & 558 & 448 \\
\hline$\sigma_{g_{2}}^{2}$ & $\begin{array}{l}\text { Genetic variance between groups in mixed } \\
\text { ponds }\end{array}$ & 2 and $19 \mathrm{~A}$ & 2053 & 1568 \\
\hline$\left(\sigma_{g_{2}}^{2}-\sigma_{g_{1}}^{2}\right)$ & $\begin{array}{l}\text { The difference between the genetic variance of } \\
\text { mixed ponds and that of separate ponds }\end{array}$ & $(18 \mathrm{~A}-19 \mathrm{~A})$ & 1495 & 1120 \\
\hline . & $\begin{array}{l}\text { Genetic covariance between groups in mixed } \\
\text { and separate ponds }\end{array}$ & 4 and $21 \mathrm{~A}$ & 1156 & 907 \\
\hline$\beta_{g}=1+\alpha$ & $\begin{array}{l}\text { Genetic regression of group means in mixed } \\
\text { ponds on separate ponds }\end{array}$ & 5 and $22 A$ & $2 \cdot 07$ & $2 \cdot 02$ \\
\hline$\rho g$ & $\begin{array}{l}\text { Genetic correlation of group means of mixed } \\
\text { and separate ponds }\end{array}$ & 6 & $1 \cdot 08$ & $1 \cdot 08$ \\
\hline $2+\alpha) \sigma_{g_{1}}^{2}$ & $\begin{array}{l}\text { The variance component of genetic magnifi- } \\
\text { cation }\end{array}$ & 3 & 1833 & 1380 \\
\hline$\sigma_{T}^{2}$ & $\begin{array}{l}\text { The variance component of independent } \\
\text { aggressiveness }\end{array}$ & $9 \mathrm{~A}$ & -338 & -260 \\
\hline
\end{tabular}

* The estimates in the columns headed by 1 and 2 were computed, respectively, from results not corrected for absolute weight and results corrected for an absolute weight of $500 \mathrm{~g}$.

accounted for by variation in separate ponds. The residual variation in mixed ponds which is independent of variation in separate ponds is relatively small and could be due to experimental errors, or specific factors operating under one set of conditions but not the other (genotype-environment interactions). Thus, the very high value of the above correlation coefficient indicates that the second factor, composed of specific genotype-environment interactions is small or absent. 
The estimate of the coefficient of regression of $d_{2}$ on $d_{1}$ was $1.5\left(\sigma_{d_{1} d_{2}} / \sigma_{d_{1}}\right.$, table 6). Its excess value over one indicated magnification of inter-group differences in mixed ponds, i.e. one unit difference in separate ponds increased to 1.5 units when the groups were co-stocked into the same mixed ponds.

The experimental results (tables 3,4 , and 5), analysed by the methods derived from the appendix, yielded estimates of the various phenotypic and genetic parameters. These estimates (table 6) constitute a summary of the results of the whole set of ten experiments. The following results are of particular interest:

(i) The inter-group genetic variance of growth rate in separate ponds $\left(\sigma_{g_{1}}^{2}\right)$ under conditions prevailing in the tests was around $500 \mathrm{~g}^{2}$, while the inter-group genetic variance of growth rate of the same groups in mixed ponds $\left(\sigma_{g_{2}}^{2}\right)$ was almost four times as high.

(ii) The estimate of the genetic correlation of growth rate in mixed and in separate ponds was one.

(iii) The estimate of the regression coefficient of growth rate in mixed ponds on growth rate in separate ponds was two, i.e. the value of the amplification factor $\alpha$ was one.

(iv) The estimate of the variance component of the independent aggressiveness $\left(\sigma_{I}^{2}\right)$ was negative. It is assumed that the true value of this parameter is zero and that the negative value of the estimate was due to sampling and measurement "errors".

The biological interpretation of these results is that in each experiment the genetic group with the faster growth rate in separate ponds was more competitive in mixed ponds and therefore its relative growth rate was even higher in the presence of inter-group competition. This result fits our earlier findings that under competition larger carp grow faster through repression of smaller carp (Wohlfarth and Moav, 1972). They are also in agreement with Magnuson's (1962) observation that in the small Cyprinodont fish "Golden medaka" (Orysias latipes) larger fish were dominant, grew faster and suppressed the growth of smaller fish when food supply was not abundant. Similar results were also reported by Greenberg (1947) in Sunfish and by Rose $(1959,1960)$ in guppies and in tadpoles.

The negative value of $\sigma_{I}^{2}$ indicates that competitiveness independent of growth capacity in separate ponds (yield capacity) was absent.

\section{Discussion}

Three genetic parameters determine the genotype's performance (relative growth rate) under competition. These are, following equation 1 , $g_{1}, \alpha$ and $I$, or following equation $9, g_{j}, \gamma_{i}$ and $I_{i j}$. $g$ is yield capacity, $\alpha$ is a population parameter determining the magnitude of the amplification by competition of inter-genotype differences and $I$ is a measure of the only "true" interaction between the genotype and the environment; "true" in the sense that it is caused by specific adaptation. $I$ is unpredictable, and is the only factor that reduces the value of the product-moment correlation coefficient below unity (Dickerson, 1962).

Many reports described experiments where different plant varieties or species were compared in pure stands and in mixtures. Some experiments were also conducted with insects, e.g. Drosophila (Ayala, 1969; Futuyma, 1970; Lewontin and Matsuo, 1963) and Tribolium (Park, 1954; Park et al., 
1964; Dawson, 1967). The many pure-stand versus mixed planting experiments in plants provided ample evidence for competition which is determined by amplification $\left(\alpha g_{1}\right)$ of differences in yield ability $\left(g_{1}\right)$. But, at the same time, almost every experiment also provided evidence for independent aggressiveness ( $I$ of equation 1 , or $I^{\prime}$ of equations 8, 9, 10 and 13) reducing, sometimes drastically, the correlation between growth rate under competition and performance in pure-stands (Christian and Gray, 1941; Suneson, 1949; Sakai, 1955, 1965; Roy, 1960; Allard, 1961 ; Harper, 1961, 1964; Jensen and Federer, 1965; Sammeta and Levins, 1970; Norrington-Davies, 1972; and others). The lack of correlation was sufficiently persistent and impressive to produce comments such as (Sakai, 1965): " That such characters as vigor, propagative capacity or fitness in pure-stand are not correlated with competitive ability is worthy of notice. Thus, the genotype, which is strong in competition but poor in fitness by itself could predominate in a population at the expense of another which is high in fitness but weak in competition." Translated into the present terminology this statement declares that independent aggressiveness (I) may be a more important contributor to the individual reproductive fitness than efficiency $\left(g_{1}\right)$, therefore natural, or artificial selection, may increase $I$ values at the expense of $g_{1}$ and this may result in reduced overall fitness of the population. The basic weakness of the above reasoning is that it overlooks the optimal solution of improving competitiveness by amplification $\left(\alpha g_{1}\right)$ rather than through increased independent aggressiveness $(I)$.

Sakai (1965) suggested that in a natural population the simultaneous selection for competitive ability and for efficiency (which he calls fitness) should result in a genetic equilibrium, since the two characters are uncorrelated. This conclusion leads to the expectation that competitive ability should have a large genetic variance and a high heritability. However, this view is contrary to that of other workers such as Mather (1961), who claimed that a low heritability for competitive ability is to be expected for any species which has undergone selection and adjustment in nature or in cultivation.

In our opinion a durable simultaneous selection for competitiveness and efficiency of utilising external resources should result in an increased correlation rather than equilibrium between the two characters. That is, the two characters should be under a single genetic control and this could be achieved by increasing $g_{1}$ and $\alpha$ and eliminating $I$ (equation 1 ).

The experiments described in this article provide empirical data on the correlation between growth rate of genetically diverse groups of carp in the presence and in the absence of inter-group competition. The results show a complete absence of competitiveness of the independent aggressiveness type $\left(\sigma_{I}^{2}<0\right.$, table 6$)$. This is compatible with the hypothesis that a single genetic control determines growth rate in the presence and absence of competition, and that competitiveness and its consequent effect on the variance of weight gain can be completely explained by variability in the weight of the fish (Wohlfarth and Moav, 1972). In other words, competitive ability independent of yield capacity, or of efficiency of exploiting external resources, is absent. However, competition does exist. It inflates the variance in mixed stocking through amplification of the genetic variability of yield capacity and it is expressed by the regression coefficient $\beta_{g}$ (equation 5 ) having a value higher than one (table 6 ). This amplification could be caused by direct competition for food, "space", "growth factors" or " environmental 
inputs", when the larger fish have an advantage over the smaller ones and they consume more than their "fair" share (de Wit, 1960; Harper, 1964). It could also be caused by social interaction (Allee et al., 1948; Magnuson, 1962) or through excretion of growth inhibiting substances by the fastergrowing individuals. Thus, Richards (1958) and Rose (1960) showed that in tadpoles accumulation of excreted substances caused growth inhibition, and that these water-borne inhibitors had a greater influence on smaller members of the population and resulted in a considerable increase in the variance of size (growth depensation).

Since the present results showed a complete correlation between competitive ability and yield capacity, they appear to be at variance with the results of many of the plant experiments mentioned above. This apparent difference could be due to real differences in the organisms under study, (cereals or legumes compared to carp), but it could also be due to a basic difference in the sampling of genotypes. Most of the competition experiments with plants were conducted with cultivated varieties developed in different locations and in response to varying requirements. This procedure is basically different from testing segregating genotypes of a single population that underwent natural selection and adjustment for many generations. In the latter case intra-population competitive ability is an integral major component of fitness and natural selection would be expected to increase its correlation with yield capacity (as described earlier). In the former case long-standing separate varieties, races or species are brought into competition by the experimenter. Inter-variety competition has then never been subjected to selection and its association with other fitness characters should be, to a large extent, coincidental and unpredictable. Hence, it is unjustified to extrapolate from inter-varietal differences to intra-population variability.

In the present experiment, assuming that the tested genotypes constituted a random sample of the population and that all the tested groups had the same intra-group genetic relationship, i.e. Full-sibs, then the inter-group genetic variance in this study should be half that of the population as a whole. Therefore, a rough estimate of the genetic variance in yield capacity, as well as, the coefficient of genetic determination of growth rate in a heterogeneous carp population, may be obtained from these results.

The genetic variance of growth rate in separate ponds for the entire population was $2 \sigma_{g_{1}}^{2}=1000 \mathrm{~g}^{2}$ (table 6). Hence, one genetic standarddeviation in growth rate in separate ponds is $33 \mathrm{~g}$, or 6-7 per cent of the mean final weight $(500 \mathrm{~g})$. Since weight gain in separate ponds is equivalent to yield capacity, a shift of one genetic SD should result in a 6-7 per cent change in yield.

Under the same assumptions the total genetic variance of carp of average weight of $500 \mathrm{~g}$ located in a single pond, under the general conditions of the present study, is roughly equal to twice the inter-group genetic variance in mixed ponds $\left(2 \sigma_{g_{2}}^{2}\right)$, i.e. 3000 to $4000 \mathrm{~g}^{2}$. Since the total phenotypic variance of carp of this average weight and under the environmental conditions prevailing in the present experiments, is approximately $10,000 \mathrm{~g}^{2}$, it appears that the total genetic determination of the phenotypic variance is of the order of 30 to 40 per cent. It may be noted that most of the genetic variance in growth rate of carp was shown to be of the non-additive kind (Moav and Wohlfarth, 1966, 1973). 
The above results and conclusions have direct applications to fish breeding. They imply that selection of individuals or groups for improving yield capacity may be carried out in mixed ponds. This is a very convenient feature because considerably higher selection intensities may be obtained when the units under selection are located within a single pond. For individual (mass) selection many thousands of fish can be grown in a single pond and therefore selection intensities can be very high. The alternative of growing each individual in a separate container not only requires a prohibitively large number of containers, it also compounds the container and genetic effects and introduces possible complications of genotype-environment interactions. Similarly group selection may be carried out in mixed ponds. We test each year 15-30 groups of carp for differences in growth rate in no more than five replicated mixed ponds (Wohlfarth and Moav, 1966). An equally powerful test in separate ponds would require hundreds of ponds. In mixed ponds the absence of compounding of genetic differences with pond differences plus the magnification of the inter-group differences due to competition makes the detection of relatively small differences between the groups much easier than in separate ponds. Another advantage of mixed ponds is that they do not have to be located in the same place or treated similarly.

\section{REFERENCES}

ALLARD, R. W. 1961. Relation between genetic diversity and consistancy of performance in different environments. Crop. Sci., 1, 127-133.

ALlEE, W. C., GREenBeRG, B., ROSENTHAL, G. M., AND FRANK, P. 1948. Some effects of social organization on growth in green Sunfish, Lepomis cyanellus. F. Exp. Zool., 108 (1), 1-19.

AYALA, F. J. 1969. Evolution of fitness IV: Genetic evolution of interspecific competitive ability in Drosophila. Genetics, 61, 737-747.

BUCIO ALANIS, L. 1966. Environmental and genotype-environment components of variability. I. Inbred lines. Heredity, 21, 387-397.

CHRISTIAN, C. s., AND GRAY, s. G. 1941. Interplant competition in mixed wheat populations and its relation to single plant selection. Counc. Sci. Indust. Res. F. (Australia), 14, 59-68.

DAwson, R. s. 1967. Developmental rate and competitive ability in Tribolium. III. Competition in unfavourable environments. F. Stored Prod., 3, 193-198.

DE WIT, c. T. 1960. On competition. Versl. van Land Order, No. 66.8.

DICKERSON, G. E. 1962. Implications of genetic-environmental interactions in animal breeding. An. Prod., 4 (1), 47-64.

Donald, c. M. 1963. Competition among crops and pasture plants. Adv. Agron., 15, 1-18.

FREEMAN, G. H., AND PERKINs, J. M. 1971. Environmental and genotype-environmental components of variability. VIII. Relations between genotypes grown in different environments and measures of these environments. Heredity, 27 (1), 15-24.

FUTUYMA, D. J. 1970. Variation in genetic response to inter-specific competition in laboratory populations of Drosophila. Am. Nat., 104, 239-252.

GREENBERG, B. 1947. Some relations between territory, social hierarchy and leadership in the green Sunfish (Lepomis cyanellus). Physiol. Zoo., 20, 267-299.

HARPER, J. L. 1961. Approaches to the study of plant competition. In: Mechanisms in Biological Competition, ed. F. L. Milthorpe. Symp. Soc. Exp. Biol., 15, 1-39.

HARPER, J. L. 1964. The nature and consequences of interference amongst plants. Genetics Today, 465-482. Pergamon Press.

HEPHER, B. 1967. Some biological aspects of warm water fish pond management. In: The Biological Bases of Fresh Water Fish Production, S. Gerkin (Ed.), pp. 417-428. Blackwell.

hickling, c. 1968. The Farming of Fish. Pergamon Press. $88 \mathrm{pp}$.

JENSEN, N. F., AND FEDERER, w. T. 1965. Competing ability in wheat. Crop. Sci., 5, 449-452.

KIRPICHNIKov, v. 1966. Goals and methods of carp selection. In: Selective Breeding of Carp and Intensification of Fish Breeding in Ponds, V. Kirpichnikov (Ed.). Bulletin of the State Scientic Research Institute of Lake and River Fisheries, Leningrad, 61, 3-23. 
LEWONTIN, R. C., AND MATsuo, Y. 1963. Interaction of genotypes determining viability in D. gusckii. PNAS, 49, 270-278.

MAGNUSON, J. J. 1962. An analysis of aggressive behaviour, growth and competition for food and space in Medaka (Orysias latipes, Pisces, Cyprinodontidae). Canadian 7. of Zoo., 40, 313-363.

MAther, K. 1961. Competition and co-operation. Symp. Soc. Exp. Biol., 15, 264-281.

MGGILCHRIST, C. A., AND TRENBATH, B. R. 1971. A revised analysis of plant competition experiments. Biometrics, 27, 659-671.

MOAV, R., AND WOHLfarth, G. 1966. Genetic improvement of yield in Carp. FAO Fish Rep., 44 (4), 12-29.

moAv, R., AND wohlfarth, G. 1973. Fish breeding in Israel. In: Agricultural Genetics Selected Topics, ed. R. Moav. J. Wiley, N.Y.

MOAV, R., WOHLFARTH, G., AND LAHMAN, M. 1960. Genetic improvement of Carp. II. Marking fish by branding. Bamidgeh, 12 (3), 49-54.

MOAV, R., WOHLFARTH, G., AND LAHMAN, M. 1964. Genetic improvement of Carp. VI. Growth rate of carp imported from Holland, relative to Israeli carp and some crossbred progeny. Bamidgeh, 16 (4), 142-149.

NORRINGTON-DAVIEs, J. 1972. Diallel analysis of competition between some Barley species and their hybrids. Euphytica, 21, 292-308.

PARK, T. 1954. Experimental studies of interspecies competition. II. Temperature, humidity and competition in two species of Tribolium. Physio. Zoo., XXVII (3), 177-238.

PARK, T., LESLIE, P. H., AND MERTZ, D. B. 1964. Genetic strains and competition in populations of Tribolium. Physio. Zoo., XXXVII (2), 97-162.

PERKINS, J. M., AND JINks, J. L. 1968. Environmental and genotype-environmental components of variability. III. Multiple lines and crosses. Heredity, 23 (3), 339-356.

RICHARDS, C. M. 1958. The inhibition of growth in crowded Rana pipiens tadpoles. Physiol. Zool., 31, 138-151.

ROY, s. K. 1960. Interaction between rice varieties. F. Genet., 57, 137-152.

ROBERTSON, A. 1959. The sampling variance of the genetic correlation coefficient. Biometrics, 15, 469-485.

Rose, s. м. 1959. Population control of guppies. Am. Mid. Nat., 62, 472-481.

ROSE, s. M. 1960. A feed back mechanism of growth control in Tadpoles. Ecology, 41 (1), 188-199.

SAKAI, K. r. 1955. Competition in plants and its relation to selection. Cold Spring Harbor Symp. on Quant. Bio., XX, 137-157.

SAKAI, K. I. 1965. Contributions to the problem of species colonization from the viewpoint of competition and migration. In: The Genetics of Colonizing Species, Ed. Baker and Stebbins, 215-241.

SAmeta, K. P. v., AND LeVins, R. 1970. Genetics and ecology. An. Rev. of Genetics., 4, 469488.

SCHAEPERCLAUS, w. 1958. Stand der Leistungsprugurgsverfahnen in der Karpfenteichwirtschaft. Dtsch. Fish-Ztg, 5 (2), 52-62.

SUNESON, C. A. 1949. Survival of four barley varieties in mixture. Agron. F., 41, 459-461. TAL, s., AND sheluBSKI, M. 1952. A review of the fish farming industry in Israel. Trans. Amer. Fish Soc., 81, 218-223.

wOHLfarTH, G. 1971. The effect of intragroup interactions on growth rate of carp in ponds and cages. Ph.D. Thesis, Jerusalem (in Hebrew).

WOHLFARTH, G., AND MOAV, R. 1966. The relative efficiency of experiments conducted in individual ponds and in ponds divided by nets. FAO Fish Rep., 44 (4), 487-492.

WOHLFARTH, G., AND MOAV, R. 1971. Genetic investigation and breeding methods of carp in Israel. Rep. FAO/UNDP (TA), (2926), 160-185.

WOHLFARTH, G., AND MOAV, R. 1972. The regression of weight gain on initial weight in carp.

I. Methods and results. Aquaculture, 1 (1), 7-28.

WOHLFARTH, G., LAHMAN, M., MOAV, R., AND ANKORION, Y. 1965. Activities of the Carp Breeding Union in 1964. Bamidgeh, 17 (1), 9-15.

yashouv, A. 1955. The Punten carp and its attributes. Bamidgeh, 7 (3), 46-55.

\section{Appendix}

Several methods for analysis of competition experiments have been suggested by various authors. For recent detailed procedures see, for $33 / 2-N$ 
example, McGilchrist and Trenbath (1971) and Norrington-Davies (1972). The specific complications that these methods had to overcome were: correlations between observations within groups, scale effects, unequal structure and magnitude of " Error " variances, larger number of parameters than independent estimates and biologically meaningful partitioning of interaction terms (as described earlier in this report). None of the reported procedures was applicable to the present results. This was due to a combination of several factors, primary among them were an unsatisfactory partitioning of the genotype-environment interaction and differences in experimental lay-outs.

Following are details of two suggested procedures of analysis based on the models of equations 2 and 9. The first procedure is applicable to experiments testing three or more different groups (genotypes) simultaneously. It combines an Analysis of Variance (ANOVA) for separate (pure-stand) ponds, an ANOVA for mixed ponds and estimation of the covariation of the group means of the two stocking methods. The second procedure, which was employed for analysing the present experiments, is applicable to a series of separate tests each involving two groups only. The two procedures overcome the bothersome complication of different "Error" variances of separate and mixed stockings and provide legitimate estimates for the variances of the two competition factors, the amplification $\left(\alpha g_{1}\right)$ and independent aggressiveness $(I)$ of equation 1 .

1. Estimation of the genetig parameters When more than two groups ARE TESTED IN A SINGLE EXPERIMENT

When $\mathcal{J}$ groups (genotypes) are tested, each in $K_{1}$ separate ponds ( $\mathcal{N}_{1}$ fish per pond), and together in $\mathrm{K}_{2}$ mixed ponds $\left(\mathcal{N}_{2}\right.$ fish per group per pond), then weight gain of an individual fish $\left(\mathbf{Y}^{\prime}\right)$ is commonly presented as the following linear function:

$$
Y_{i j k n}^{\prime}=\mu+a_{i}+g_{j}+(g a)_{i j}+c_{i j k}+e_{i j k n}
$$

When $\mu=$ grand mean over the two stocking methods (environments),

$a_{i}=$ the "environment" effect, or the deviation of the mean of the $i$ th stocking method from $\mu$,

$g_{j}=$ the average group effect, or deviation of the $j$ th group from its mean over the two environments,

$(\mathrm{ga})_{i j}=$ the genotype-environment interaction,

$c_{i j k}=$ the "common-environment" effect of the $k$ th sample (in separate ponds it includes the " pond effect") and,

$e_{i j k n}=$ the "individual fish" effect.

Note that equation $1 \mathrm{~A}$ is equal to equation 7 of the text with the addition of the general mean $\mu$ and the two "Error" terms $c$ and $e$.

In the present study $\left(\mu+a_{i}\right)$ is of no interest, also the unit of measurement is not an individual fish but the mean of all the fish of the $k$ th sample. Therefore, equation $1 \mathrm{~A}$ was simplified into

$$
Y_{i j k}=\left(Y_{i j k .}^{\prime}-\left(\mu+a_{i}\right)=g_{j}+(g a)_{i j}+E_{i j k}\right. \text {. }
$$

When dot in the index designates a mean value, and by definition:

$$
E_{i j k}=c_{i j k}+e_{i j k}
$$


Analysis of variance (ANOVA) of weight gains in separate ponds (Environment 1)

Here $i=1$, and equation 2A can be expressed as,

$$
Y_{1 j k}=g_{1 j}+E_{1 j k} \text {. }
$$

This describes a simple case of one-way ANOVA (randomised plot design) where an individual observation is the mean of a separate pond. Table 1A shows the two relevant Mean-Squares (MS) of the ANOVA and their

\section{TABLE 1A}

Analysis of variance ( $A \mathcal{N O V A}$ ) tables for analysis of differences between groups (genotypes) in separate and mixed stocking

( $\mathrm{Y}$ in the tables is equal to $\mathrm{y}^{\prime}$ of equation $1 \mathrm{~A}$ )

Source

Separate ponds $(i=1)$

Between groups

$\left(M S_{g_{1}}\right)$

Between ponds

$\left(M S_{E_{1}}\right)$

Mixed ponds $(i=2)$

Between groups

$\left(M S_{g_{2}}\right)$

Pond-group interaction $\left(M S_{E_{2}}\right)$ d.f.

MS
E(MS)

$$
\mathcal{J}\left(K_{1}-1\right) \quad \frac{1}{\mathcal{J}\left(\bar{K}_{1}-1\right)} \sum_{j k} \sum_{1 j k}-\frac{1}{K_{1}} \sum_{j}\left(\sum_{k} \mathrm{Y}_{1 j k}\right)^{2} \quad \sigma_{E_{1}}^{2}
$$

$$
\begin{aligned}
& \text { J-1 }
\end{aligned}
$$

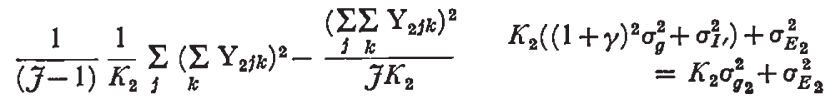

$$
\begin{aligned}
(\mathcal{J}-1)\left(K_{2}-1\right) & \frac{1}{(\mathcal{J}-1)\left(K_{2}-1\right)} \sum_{j} \sum_{k} \mathrm{Y}_{2 j}^{2}-\frac{1}{K_{2}} \sum_{j}\left(\sum_{k} \mathrm{Y}_{2 j k}\right)^{2} \\
& -\frac{1}{\mathcal{J}} \sum_{k}\left(\sum_{j} Y_{j k}\right)^{2}+\frac{\left(\sum \sum \mathrm{k}_{2} j\right.}{\left.\mathcal{J} K_{2}\right)^{2}}
\end{aligned}
$$

expectations (E(MS)). Through these values an estimate of the inter-group (genetic) variance $\sigma_{g_{1}}^{2}$ can be computed,

$$
\hat{\sigma}_{g_{1}}^{2}=\frac{M S_{g_{1}}-M S_{E_{1}}}{K_{1}}
$$

Note that the symbol ^ signifies an estimate, and that $M S_{E_{1}}=\hat{\sigma}_{E_{1}}^{2}$.

ANOVA in mixed ponds (Environment 2)

Here $i=2$,

$$
Y_{2 j k}=g_{2 j}+c_{2 k}+E_{2 j k}
$$

and we have a two-way ANOVA (randomised blocks design). Note that the pond effect $\left(c_{2 k}\right)$ can be separated from $E$, hence the " error " components $E_{1}$ (Environment 1) and $E_{2}$ (Environment 2) are composed of different elements. From table $1 \mathrm{~A}$ we may derive an estimate for $\sigma_{g_{2}}^{2}$,

$$
\hat{\sigma}_{g_{2}}^{2}=\frac{M S_{g_{2}}-M S_{E_{2}}}{K_{2}} .
$$

Also, $\hat{\sigma}_{E_{2}}^{2}=M S_{E_{2}}$. 
Analysis of the covariation between the two stocking methods (environments)

The mean performances of the $j$ th group in Environments 1 and 2 are, respectively (following equations $3 \mathrm{~A}$ and $5 \mathrm{~A}$, and equation $\mathrm{l}$ of the text),

and

$$
Y_{1 j .}=g_{1 j}+E_{1 j}
$$

$$
Y_{2 j}=(1+\alpha) g_{1 j}+I_{j}+E_{2 j} \text {. }
$$

Note that $\mathrm{Y}_{2 j}$. are defined as deviations around the means of individual mixed ponds, hence the absence of $c_{2 k}$ (of equation $5 \mathrm{~A}$ ) from the last equation. The covariance between the paired observations $\left(Y_{1 j}, Y_{2 j}\right.$. $)$ is primarily of genetic origin and its expected value was presented in equation 4 of the text as a function of $\alpha$ and $\sigma_{\theta_{1}}^{2}$.

Similarly, the genetic regression $(\beta g)$ of $g_{2}$ on $\mathrm{g}_{1}$ and their genetic correlation $\left(\rho_{g}\right)$ were defined in equations 5 and 6 . Substitution of estimates for $\sigma_{12}, \sigma_{g_{1}}^{2}$ and $\sigma_{g_{2}}^{2}$ (table $1 \mathrm{~A}$ and equations $4 \mathrm{~A}$ and $6 \mathrm{~A}$ ) in equations 5 and 6 provide estimates for $\beta g$ and $\rho g$. Using the relationship $\beta g=(1+\alpha)$, and rearranging equation 2 (text) results in,

$$
\sigma_{I}^{2}=\sigma_{g_{2}}^{2}-\beta_{g}^{2} \sigma_{g_{1}}^{2} .
$$

Substitution of estimates for the factors on the right side of this equation provides an estimate for $\sigma_{I}^{2}$.

2 Estimation of the genetic parameters WHEN ONLy a single pair of GROUPS (GENOTYPES) IS TESTED IN EAGH ONE OF A SERIES OF SEVERAL EXPERIMENTS

Frequently, shortage of facilities does not permit the testing of more than one pair of groups in a single experiment, but several $(M)$ experiments may be performed consecutively. This was the case in the present study. Under these circumstances, $I=2$ (environments, stocking methods) and also $\mathcal{J}=2$ (tested groups in a single experiment).

The differences in the $m$ th experiment, between the average performances of the pair of tested groups in separate ponds $\left(d_{m_{1}}\right)$ and mixed ponds $\left(d_{m_{2}}\right)$ are, respectively (following equation $7 \mathrm{~A}$ and $8 \mathrm{~A}$ ),

and

$$
d_{m_{1}}=\left(Y_{m_{11}}-Y_{m_{12}} .\right)=\left(g_{m_{11}}-g_{m_{12}}\right)+\left(E_{m_{11}}-E_{m_{12}}\right)
$$

$d_{m_{2}}=\left(Y_{m_{21}}-Y_{m_{22} .}\right)=\beta_{g}\left(g_{m_{11}}-g_{m_{12}}\right)+\left(I_{m_{1}}-I_{m_{2}}\right)+\left(E_{m_{21}}-E_{m_{22}}\right)$.

In general, the variable $d$ was defined as $d=\left(\mathrm{Y}_{1}-\mathrm{Y}_{2}\right)$ when, post-hoc, the index 1 was assigned to the larger of the $Y^{\prime} s\left(Y_{1}>Y_{2}\right)$. When $Y_{1}$ and $Y_{2}$ are chosen independently and at random from a population of $Y$ 's, then the variable $d$ has an expectation of zero and its variance is,

$$
\sigma_{d}^{2}=E\left(d^{2}\right)=2 \sigma_{y}^{2}
$$

The $M$ experiments provide a series of $M$ pairs $\left(d_{m_{1}}, d_{m_{2}}\right)$ whose variances and covariances can be estimated directly from the experimental results.

$$
\hat{\sigma}_{d_{1}}^{2}=s_{d_{1}}^{2}=\frac{1}{M} \sum^{M} d_{m_{1}}^{2}
$$




$$
\hat{\sigma}_{d_{2}}^{2}=s_{d_{2}}^{2}=\frac{1}{M} \sum^{M} d_{m_{2}}^{2}
$$

and

$$
\hat{\sigma}_{d_{1} d_{2}}=s_{d_{1} d_{2}}=\frac{1}{M} \sum^{M} d_{1} d_{2}
$$

Note that because of the assignment of $Y_{1}>Y_{2}$ the above estimates can not be of the general form

$$
s_{d_{1} d_{2}}=\left(\Sigma\left(d_{1}-d_{1} .\right)\left(d_{2}-d_{2} .\right) /(m-1)\right) .
$$

The mean variance between separate ponds of the same group (over all the experiments) may serve as an estimate for $\sigma_{E_{1}}^{2}$.

$$
\hat{\sigma}_{E_{1}}^{2}=s_{E_{1}}^{2}=\frac{\sum^{M} \sum^{J}\left(\sum^{K_{1}}\left(Y_{1 m j k}-Y_{1 m j}\right)^{2}\right)}{\sum^{M} \sum^{J}\left(K_{1 j m}-1\right)} .
$$

On the other hand, the estimate of $\sigma_{E_{2}}^{2}$ should be based on the variance of deviations of each group from the means of the individual mixed ponds,

$$
\hat{\sigma}_{E_{2}}^{2}=s_{E_{1}}^{2}=\frac{\sum^{M} \sum^{J}\left(\sum^{K_{2}}\left(Y_{2 m j k}-Y_{2 m, k}\right)^{2}\right)}{\sum^{M} \sum^{J}\left(K_{2 m j}-1\right)} .
$$

Following equation $10 \mathrm{~A} \sigma_{d_{1}}^{2}$ can be expressed as,

$$
\sigma_{d_{1}}^{2}=2\left(\sigma_{g_{1}}^{2}+\sigma_{E_{1}}^{2}\right)
$$

Rearrangement and substitution of estimates for $\sigma_{d_{1}}^{2}$ (equation 13A) and for $\sigma_{E_{1}}^{2}$ (equation 16A) provides an estimate for $\sigma_{g_{1}}^{2}$,

$$
\hat{\sigma}_{g_{1}}^{2}=\frac{s_{d_{1}}^{2}}{2}-\hat{\sigma}_{E_{1}}^{2} .
$$

Similarly,

and

$$
\sigma_{d_{2}}^{2}=2\left(\beta_{g}^{2} \sigma_{g_{1}}^{2}+\sigma_{I}^{2}+\sigma_{E_{2}}^{2}\right)
$$

$$
\hat{\sigma}_{g_{2}}^{2}=\frac{s_{d_{2}}^{2}}{2}-\hat{\sigma}_{E_{2}}^{2}
$$

The covariance $\sigma_{d_{1} d_{2}}$ equals twice the genetic covariance $\sigma_{12}$,

$$
\sigma_{d_{1} d_{2}}=2 \beta_{g} \sigma_{g_{1}}^{2}=2 \sigma_{12}
$$

Hence,

$$
\hat{\sigma}_{12}=\frac{s_{d_{1} d_{2}}}{2}
$$

$33 / 2-\mathrm{N} 2$ 
Substitution of estimates for $\sigma_{g_{1}}^{2}$ (equation 18A) and for $\sigma_{12}$ (the last equation) and rearrangement of equation $20 \mathrm{~A}$ provides an estimate for $\beta_{g}$,

$$
\hat{\beta}_{g}=\frac{\hat{\sigma}_{12}}{\hat{\sigma}_{g_{1}}^{2}}=\frac{s_{d_{1} d_{2}}}{\left(s_{d 1}^{2}-2 s_{E_{1}}^{2}\right)} .
$$

Finally, substitution of the estimates of equations 18A, 19A and 22A on the right side of equation $9 \mathrm{~A}$ provides an estimate for $\sigma_{I}^{2}$. 